\title{
O CARÁTER ONTOLÓGICO DA FILOSOFIA DE FEUERBACH SEGUNDO LUKÁCS
}

\author{
Fátima Maria Nobre Lopes ${ }^{1}$
}

\begin{abstract}
Resumo
O presente artigo tem o objetivo de dissertar sobre o caráter ontológico da filosofia de Feuerbach tomando o pensamento de Lukács a partir da sua obra Ontologia do Ser Social. Demonstra que, embora nessa obra Lukács não trate especificamente de tal questão, ele vai delineando em várias partes da sua Ontologia os limites e a importância da filosofia de Feuerbach destacando-se, nesse último ponto, uma ontologia autêntica do ser social. Tal importância refere-se, principalmente, pela viragem ontológica de Feuerbach em relação à Hegel. Podemos afirmar que o caráter ontológico da filosofia de Feuerbach consiste justamente em protagonizar uma virada ontológica ao sustentar a materialidade do ser, pois, para ele, a verdade é o homem e a vida, e não a razão abstrata ou o pensamento desligado do real. Em suma, trata-se da relação material entre o ser e o pensar, cuja primazia é do ser, quer dizer, o ser se sobrepõe ao pensar. Todas essas considerações deram à Feuerbach um estatuto ontológico materialista da sua filosofia que irá influenciar fortemente Marx, Engels, e depois Lukács na concepção e estruturação da ontologia do ser social.Para tratarmos dessas questões dividimos o trabalho em três partes. Na primeira fazemos uma breve apresentação da obra de Lukács a Ontologia do Ser Social; na segunda destacamos a posição de Lukács ao fazer uma analogia do pensamento de Feuerbach ao de Hartmann quanto à natureza do ser; na terceira parte, à guisa de conclusão,tratamos das contribuições de Feuerbach como fio condutor da ontologia marxiana.
\end{abstract}

Palavras-Chave: Ontologia; Ser Social; Natureza do Ser.

\section{THE ONTOLOGICAL CHARACTER OF FEUERBACH PHILOSOPHY ACCORDING LUKÁCS}

\begin{abstract}
This article aims to elaborate about ontological character of the Feuerbach philosophy taking the thought of Lukács from your Ontology of Social Being. It shows that, although Lukács, in his ontology, not specifically dealing with this question, he will outlining in various parts of his Ontology limits and the importance of the philosophy of Feuerbach highlighting, on that last point, an authentic ontology of social being. Such importance refers mainly by ontological turn Feuerbach in relation to Hegel. We can say that the ontological character of Feuerbach's philosophy is precisely to starring in an ontological turn to support the materiality of being, because, for him, the truth is the man and life, not abstract reasoning or thinking disconnected from the real. In short, it is the material connection between being and thinking, whose primacy is of being, that is,

\footnotetext{
${ }^{1}$ Graduada e Mestre em Filosofia e Doutora em Educação. Professora de Filosofia da UFC/FACED, Departamento de Fundamentos da Educação. Membro do Programa de Pós-Graduação (Mestrado e Doutorado) em Educação Brasileira da UFC. Pesquisadora do LABOR - Laboratório de Estudos do Trabalho e Qualificação Profissional. Líder dos Grupos de Pesquisa, ambos certificados pelo CNPq: "Ontologia do Ser Social, Ética e Formação Humana" e do "Grupo de Estudo e Pesquisa em Ensino de Filosofia - GEPEFI".
} 


\section{O CARÁTER ONTOLÓGICO DA FILOSOFIA DE FEUERBACH...}

\section{Fátima Maria Nobre Lopes}

being overlaps in thinking. All these considerationsgave to Feuerbacha materialistontological statusof his philosophythat willstrongly influenceMarx, Engels, and thenLukácsin the design andstructureof the ontologyof social being. Totreatthese issuesdivided the workinto three parts. At first we make a brief presentation of the work of Lukács the Ontology of Social Being; in the second we highlight the Lukács position to make an analogy of thought of Feuerbach to the Hartmann about the nature of being; in the third part, by way of conclusion, we treat the contributions as Feuerbach thread of Marxian ontology.

Key-words: Ontology; Social Being; Nature of Being.

\section{Introdução}

Antes de desenvolver, na sua obra Ontologia do Ser Social, o edifício conceitual no qual demonstra as bases da vida social dos homens por meio das categorias trabalho, reprodução, ideologia e estranhamento, Lukács nos apresenta quatro capítulos introdutórios, quais sejam: "Neopositivismo e Existencialismo"; "O avanço de Nicolai Hartmann em direção a uma verdadeira ontologia"; "A falsa e a verdadeira ontologia de Hegel"; "Os princípios ontológicos fundamentais de Marx". Para desenvolver toda a base conceitual da sua Ontologia cujo pressuposto é o pensamento de Marx, Lukács busca elementos nas teses de Hegel, Feuerbach e Hartmann, embora no seu duplo aspecto, ou seja, ora elogiando, ora criticando partes da concepção desses pensadores.

É por esse viés que Lukács vai considerar a filosofia de Feuerbach como uma das bases da ontologia marxiana. É certo que ele não direciona uma parte exclusiva da sua Ontologia ao pensamento de Feuerbach, porém ao destacar a positividade da ontologia de Hartmann e ao evidenciar os princípios ontológicos fundamentais de Marx ele vai delineando o caráter ontológico da filosofia de Feuerbach, sem contar com algumas notas esparsas no decorrer de toda a sua obra, quando, em momentos necessários,Lukács remete ao pensamento de Feuerbach.

A nossa exposição irá consistir, dessa forma, em três partes. Na primeira iremos fazer uma breve apresentação da obra de Lukácsa Ontologia do Ser Social; na segunda destacaremos a posição de Lukács ao fazer uma analogia do pensamento de Feuerbach ao de Hartmann quanto à natureza do ser; na terceira parte, à guisa de conclusão,falaremos das contribuições de Feuerbach como fio condutor da ontologia marxiana.

\begin{tabular}{|l|l|l|l|l|}
\hline Qenista Qialectus & Ano 2 & n. 6 & Janeiro - Agosto 2015 & p. 120-129 \\
\hline
\end{tabular}




\section{O CARÁTER ONTOLÓGICO DA FILOSOFIA DE FEUERBACH...}

\section{Fátima Maria Nobre Lopes}

\section{1- A Ontologia do Ser Social de Lukács: uma apresentação}

Em contraposição à ontologia clássica que se detinha às questões puramente metafísicas, a ontologia do ser social encontra a base real do ser nas relações concretas entre o homem e a natureza, bem como nas relações sócio-históricas que delas decorrem. Nesse sentido, a ontologia de novo tipo não é pré-existente ao real e sim a posteriori, porisso ela é fundada e fundante, manifestando a objetividade do real e o seu caráter ontológico-prático.

Hegel forneceu elementos para essa instauração da ontologia moderna, porém permanece no nível da especulação. Embora em suas diversas obras, principalmente na Enciclopédia das Ciências Filosóficas (1992),demostre a processualidade histórica e dialética do ser, Hegel cai num idealismo ao considerar a Idéia ou Razão como o fundamento da realidade, perdendo a dimensão prática do homem. Também Feuerbach, em oposição à Hegel, forneceu elementos para essa ontologia do novo tipo, porém perdeu a dimensão histórica e processual do homem.

No entanto, é Marx, com suas influências de Hegel e de Feuerbach, quem traz à luz uma nova ontologia ao iniciar as suas primeiras reflexões críticas e antiespeculativas. ${ }^{2}$ Tomando como premissa a própria dialética hegeliana, mas partindo do homem concreto e sensível, como defendia Feuerbach, e acrescentando a dimensão histórica e processual do homem e do contexto social como fundamento do ser, Marx inaugura toda uma fundamentação da ontologia do ser social, cujos pressupostos são os homens nas relações sociais de produção e reprodução e no estabelecimento da sua sociabilidade. Diz Marx (1964): “o indivíduo é o ser social. A manifestação de sua vida constitui uma expressão e uma confirmação da vida social" (p. 195-196). Portanto, a essência ontológica do homem compreende as suas próprias relações sociais, não como algo externo a ele, mas como parte constitutiva do seu ser, compreendendo a sua própria práxis, daí porque "todos os mistérios que induzem a teoria para o misticismo encontra solução racional na práxis humana e na compreensão dessa práxis” (Marx, 1984, p. 128)

Apesar de Marx jamais ter tratado sistematicamente de uma ontologia e das categorias que a compõem, no entanto elas se encontram delineadas em suas vastas obras,

\footnotetext{
${ }^{2}$ Marx louva Hegel por considerar a história como processo de formação do homem, porém o critica por considerar como fundamento desse processo a Idéia, o Espírito, a Lógica. A esse respeito ver Marx, $A$ Sagrada Família, s/d, p. 119.
}

\begin{tabular}{|l|l|l|l|l|}
\hline Renita 2 ialectus & Ano 2 & n. 6 & Janeiro - Agosto 2015 & p. 120-129 \\
\hline
\end{tabular}




\section{O CARÁTER ONTOLÓGICO DA FILOSOFIA DE FEUERBACH...}

\section{Fátima Maria Nobre Lopes}

principalmente naquelas de juventude. É importante frisar que toda a inspiração da crítica de Marx ao pensamento hegeliano encontra fundamento no materialismo de Feuerbach, embora Marx o critique posteriormente em outros pontos.

Lukács, filósofo húngaro e pensador contemporâneo, vai resgatar a questão ontológica posta por Marx. Utilizando-se das categorias sociais tematizadas por Marx, ele reconstrói a sua filosofia e instaura os fundamentos de uma ontologia do ser social. Portanto, fiel ao método ontológico-genético marxiano, Lukács expõe uma concepção dialética da gênese e desenvolvimento do ser humano nas suas relações histórico-sociais. Essa temática está exposta na sua clássica obra de maturidade Ontologia do Ser Social ${ }^{3}$ na qual ele demonstra as esferas do ser e desenvolve toda uma teoria do gênero humano apresentando as categorias centrais que constituem a vida social dos homens: trabalho, reprodução, ideologia, estranhamento. Como dissemos no início, essas categorias são precedidas pela sua crítica ao Neopositivismo e pelos delineamentos da ontologia de Hartmann, Hegel e Marx, por meio dos quais ele vai evidenciando também o caráter ontológico da filosofia de Feuerbach.

Em verdade Lukács tinha a pretensão de escrever uma obra sobre ética que deveria ser precedida por uma introdução, na qual seriam examinados os componentes fundamentais e a estrutura da vida social. Tal Introdução se tornou a sua vasta Ontologia, pois, ao perceber que seria preciso não apenas uma introdução à ética, mas sim o desenvolvimento de uma ontologia sem a qual seria impossível uma fundamentação convincente acerca da ética, os seus trabalhos introdutórios transformaram-se no volumoso manuscrito Ontologia do Ser Social acompanhado dos seus Prolegômenos à Ontologia do Ser Social ${ }^{4}$ que vieramà luz após a Ontologia.

\footnotetext{
${ }^{3}$ A Ontologia do Ser Social é composta, na edição italiana, por três volumes, publicados pela editora Riuniti em 1976 (vol. I) e em 1981 (vol. II* e vol. II**), com o títulode:Ontologia Dell'EssereSociale. Já na edição brasileira ela é composta por dois volumes, publicada pela Boitempo, em 2012 o vol. I e em 2013 o vol. II, com o título de:Para uma Ontologia do Ser Social. Antes dessa edição já havia sido publicada em Português duas partes do Vol. I da Ontologia, quais sejam: Os Princípios Ontológicos Fundamentais de Marxe A Falsa e a Verdadeira Ontologia de Hegel, ambas publicadas em 1979 pela Editora Ciências Humanas. Todas essas edições foram pesquisadas para a elaboração do presente escrito.

4 Essa obra de Lukács, da edição italiana Guerini e Associati, 1990, com o título ProlegominiAll'OntologiaDell'EssereSociale, foi redigida em 1970, após o término da Ontologia. Segundo Tertulian, o motivo de Lukács ter escrito os Prolegômenos da Ontologia após a conclusão desta, em termos de conjecturas, talvez seja pelo fato de ele ter sentido "a necessidade de expor, em forma mais condensada..., as idéias mestras do seu trabalho e os seus objetivos" (Tertulian, 1996, p. 55). Por essa razão os Prolegômenos repetem várias idéias centrais da Ontologia. Tertulian comenta que os Prolegômenos tinham "por objetivo fixar os pontos básicos da Ontologia" (idem, p. 56).
}

\begin{tabular}{|l|l|l|l|l|}
\hline Ronista Cialeatus & Ano 2 & n. 6 & Janeiro - Agosto 2015 & p. 120-129 \\
\hline
\end{tabular}




\section{O CARÁTER ONTOLÓGICO DA FILOSOFIA DE FEUERBACH...}

\section{Fátima Maria Nobre Lopes}

Mesmo não tendo escrito sistematicamente a sua Ética, Lukács nos deixou a Ontologia como um eixo condutor para a sua compreensão e análise. As considerações acerca das categorias sócio-históricas são a condição essencial para a elaboração de uma ética, pois, para o nosso autor, não existe ética sem ontologia. Enfim, é na Ontologia que está fundamentado o caráter histórico e social da ética cuja direção central é a possibilidade de elevação do ser a valores humano-genéricos, compreendendo a sua própria constituição ontológica. Feuerbach deu uma aproximada (embora numa outra direção) dessa ontologia ao reconhecer o homem como um ser sensível e ao refutar o idealismo hegeliano.

Portanto, o estudo das categorias fundamentais da existência humana constitui o objeto precípuo da Ontologia de Lukács cujo objetivo central é compreender e demonstrar a complexificação da vida social, definindo o homem como um ser que responde às suas necessidades e aos problemas que delas emergem. Em suma, na Ontologia do Ser SocialLukács se propôs a desenvolver uma teoria do gênero humano, apresentando as categorias ontológicas fundamentais da vida social dos homens. Para tanto, ele resgata elementos do pensamento de Hartmann, Hegel, Feuerbach, culminando com o pensamento de Marx.

\section{O caráter ontológico da filosofia de Feuerbach: analogia ao pensamento de Hartmann quanto à natureza do ser.}

Falando do progresso de Hartmann em direção a uma verdadeira ontologia, Lukács, ao mesmo tempo, defende o caráter ontológico da filosofia de Feuerbach. Porém ele nos chama a atenção de que a filosofia desses dois pensadores de modo algum pode ser entendida no sentido de uma semelhança direta. Até porque Feuerbach, na metade do século XIX, embora tenha se destacado pelo seu debate contra o idealismo hegeliano, permanece "do começo ao fim um outsider ${ }^{5}$ na filosofia alemã defendendo isoladamente sua posição até mesmo na época dos seus êxitos mais retumbantes" (Lukács, 2012,vol. I,p. 130), ao passo que Hartmann, um século depois, "se move em um vasto território; suas investigações se estendem por todos os campos do mundo do saber" (idem).

No entanto,a semelhança dos dois pensadores consiste no fato de "ambos terem apreendido um complexo de problemas central em seu tempo com grande intensidade, perspicácia persuasiva e senso para o real [...] ao filosofar contra a corrente de sua época, eles direcionaram os seus esforços de modo certeiro" (Lukács, idem, p. 130). Esse é o

${ }^{5}$ Outsider, quer dizer, um pensador isolado, fora do meio filosófico da época (nota nossa).

\begin{tabular}{|c|c|c|c|c|}
\hline Q Rovista Dialectus & Ano 2 & n. 6 & Janeiro - Agosto 2015 & p. $120-129$ \\
\hline
\end{tabular}




\section{O CARÁTER ONTOLÓGICO DA FILOSOFIA DE FEUERBACH...}

\section{Fátima Maria Nobre Lopes}

ponto central e positivo da filosofia de Feuerbach e de Hartmann: "o senso para o real", e a maneira como "esses dois pensadores extremamente talentosos descobriram problemas centrais" cuja direção é considerar o ser material, vivente, real e sensível.

Em relação à Feuerbach, Lukács comenta que ele inverteu de maneira materialista a relação "Deus-ser-humano", além do mais "deu um impulso decisivo para a dissolução do hegelianismo" (idem, p. 131), livrando as questões de caráter teológicas e ideológicas de"beco sem saída", confrontando o sistema hegeliano com a própria realidade. É certo que Feuerbach ao transformar os problemas teológicos em problemas antropológicos "não foi capaz de estender suas ideias antropológicas ao ser humano concreto, ao ser humano histórico-social" (idem, p. 131). Não obstante, ele defende a natureza objetiva do ser, considerando o homem na sua dimensão sensível e corpórea. Aqui consiste, sobretudo, o caráter ontológico da filosofia de Feuerbach que desembocará no pensamento de Marx e de Lukács em relação à natureza objetiva do ser, destacando a sua dimensão histórica e social.

Todo o fundamento do caráter ontológico da filosofia de Feuerbach tem a sua origem quer seja na sua crítica à religião, quer seja na crítica que ele faz a Hegel.

No que diz respeito ao primeiro ponto Feuerbach diz que a relação do homem com o objeto, "mesmo no tocante aos objetos sensoriais, é válido em especial para a relação do mesmo com o objeto religioso" (Feuerbach, 1988, p.55); porém o objeto sensível é indiferente, independe da intenção, mas o objeto da religião é mais selecionado, é um ser mais excelente. Em qualquer caso, no entanto, o objeto do homem, sensível ou religioso, "nada mais é do que o homem objetivado" (idem, p. 55). Desse modo, "a consciência de Deus é a consciência que o homem tem de si mesmo, o conhecimento de Deus o conhecimento que o homem tem de si mesmo" (idem). A essência divina nada mais é do que a essência humana, ou seja, o homem real, corpóreo, sensível. Podemos perceber que Feuerbach transporta para o plano ontológico materialista a questão de Deus ${ }^{6}$.

No tocante à Hegel, Feuerbach considera que a sua filosofia não deixa de ser uma variante da teologia a partir do momento em que ele faz das determinações do homem as determinações divinas: "o segredo da teologia é a antropologia, porém o segredo da filosofia especulativa é a teologia - a teologia especulativa” (Feuerbach, 1976a, p. 03). Hegel considera a arte, a religião e a filosofia como manifestações do Espírito Absoluto, ao

\footnotetext{
${ }^{6}$ Falando do rei da Prússia que havia decretado uma ordem militar onde se podia ler: "se não fosse a ajuda de Deus", Feuerbach comenta: "que ajuda de Deus é essa que não tem sucesso e nem poder sem baionetas e nem balas? (Feuerbach, Preleções sobre a Essência da Religião, 2009, p. 190)
}

\begin{tabular}{|l|l|l|l|l|}
\hline Q Povista Dialectus & Ano 2 & n. 6 & Janeiro - Agosto 2015 & p. 120-129 \\
\hline
\end{tabular}




\section{O CARÁTER ONTOLÓGICO DA FILOSOFIA DE FEUERBACH...}

Fátima Maria Nobre Lopes

passo que, para Feuerbach, são manifestações do próprio homem, quer dizer, da própria comunidade humana uma vez que "a arte e a religião não podem separar-se dos sentimentos, da fantasia e da intuição humanas, e nem a filosofia pode separar-se do pensar" (idem, p. 07).

A viragem ontológica de Feuerbach em relação à Hegel consiste, então, na sua afirmação de que a verdadeira relação entre o pensar e o ser consiste no seguinte: "o pensar procede do ser, mas não o ser do pensar" (Feuerbach, idem,p. 21).Em outro escrito Feuerbach complementa essa ideia afirmando que um "um ser que só é um predicado ou uma determinação da razão não é um ser" (Feuerbach, 1976b, p. 71). Mais tarde Marx (1964) diránesse mesmo sentido de Feuerbach: "um ser não objetivo é um não ser". Feuerbach defende uma relação materialista entre o ser e o pensar. Para ele, assim como para Marx e Lukács, é a materialidade do ser que constitui o fundamento e a geração do pensar e das ideias.

Ao falar dos aspectos ideológicos do estranhamento na sua OntologiaLukácsdiz que Feuerbach revelou a questão ontológica sobre a materialidade do ser contribuindo para ampliar o debate de então que se concentrava no campo gnosiológico e/ou idealista. Diz Lukács: sem a contribuição de Feuerbach "a dissolução da escola hegeliana seria facilmente reduzida a uma discussão entre professores e literatos, sem produzir nada de filosoficamente essencial que pudesse ir além de Hegel” (Lukács, 1981, vol. II**, p. 620).

Em outra passagem da OntologiaLukács destaca: "não há dúvida que a virada provocada por Feuerbach no processo de dissolução do hegelianismo teve caráter ontológico" (Lukács, 1979a, p. 12). Desse modo, pela primeira vez na Alemanha "foram confrontados abertamente - com efeitos extensos e profundos - o idealismo e o materialismo" (idem). Tudo isso contribuiu "para fazer emergir o problema ontológico" (idem). Podemos encontrar aqui claramente o caráter ontológico da filosofia de Feuerbach, embora com suas limitações, que influenciará fortemente o pensamento de Marx.

\section{3. À Guisa de Conclusão: as contribuições de Feuerbach como fio condutor da ontologia marxiana.}

Ao falar dos princípios ontológicos fundamentais de Marx na sua Ontologia Lukács destaca que a crítica de Feuerbach à teologia e ao idealismo hegeliano conduziu a uma nova orientação ontológica uma vez que Marx vai retomar tais críticas como ponto de

\begin{tabular}{|l|l|l|l|l|}
\hline Q Rovista Dialectus & Ano 2 & n. 6 & Janeiro - Agosto 2015 & p. 120-129 \\
\hline
\end{tabular}




\section{O CARÁTER ONTOLÓGICO DA FILOSOFIA DE FEUERBACH...}

\section{Fátima Maria Nobre Lopes}

partida da sua concepção de homem como ser histórico e social. Portanto, diz Lukács:“a nova orientação ontológica iniciada com Feuerbach atua logo a partir do seu surgimento" (Lukács, 1979a, p. 12). Trata-se, aqui, da ontologia do novo tipo: a ontologia do ser social.

Portanto, ainda que Feuerbach não tenha considerado a dimensão ativa e histórica do homem, Lukács chama a atenção de que Marx reconhece a virada ontológica de Feuerbach "como o único ato filosófico sério desse período" (Lukács, idem, p. 13). Embora Marx tenha avançado em relação à Feuerbach tanto na crítica (à religião, ao hegelianismo, e até mesmo à economia política), ele "pôs-se imediatamente de acordo, em princípio, com as ideais de Feuerbach acerca da ontologia da natureza e com a sua atitude anti-religiosa" (Lukács, idem, p. 15).

Mais uma vez, ao tratar dos aspectos ideológicos do estranhamento na sua Ontologia, Lukács (1981, vol. II**) destaca as contribuições de Feuerbach para o pensamento Marxiano.Nos Manuscritos econômico-filosóficos diz Marx, citado por Lukács:"Feuerbach é o único que tem uma relação séria com a dialética hegeliana e o único que fez verdadeiras descobertas nesse domínio, sendo em toda linha o verdadeiro triunfador sobre a velha filosofia” (Marx, apud Lukács, 2013,vol. II, p. 640-641).

É certo que Marx posteriormente crítica Feuerbach pelas limitações do seu materialismo, principalmente por não reconhecer a dimensão histórica e ativa do homem, pois, "na medida em que Feuerbach é materialista nele não se encontra a história, e, na medida em que toma em consideração a história, ele não é materialista. Nele, materialismo e história divergem completamente [...]" (Marx, apud Lukács, idem, p. 641).

Não obstante as limitações da filosofia de Feuerbach, ela foi a mola propulsora da ontologia marxiana. Dentre outros méritos o próprio Marx destaca nos Manuscritos Econômico-Filosóficos ao afirmar que o grande empreendimento de Feuerbach é: "1) a prova de que a filosofia constitui apenas a religião convertida em pensamento e desenvolvida pelo pensamento [...]; 2) a fundamentação do autêntico materialismo e da ciência positiva, na medida em que Feuerbach faz da relação social do 'homem ao homem' o princípio da sua teoria” (Marx, 1964, p. 239-240).

Por fim, a crítica de Feuerbach à religião e à teologia bem como à onipotência ontológica da Razão hegeliana ao sobrepor o pensar ao ser $^{7}$, deram à Feuerbach um

\footnotetext{
${ }^{7}$ Segundo Feuerbach (1976a),Hegel exerceu uma inversão nessa relação. Tal inversão está expressa principalmente na religião e na teologia por meio das quais o homem é dominado e subjugado às representações de Deus.
}

\begin{tabular}{|l|l|l|l|l|}
\hline Q & Dovista \\
\hline
\end{tabular}




\section{O CARÁTER ONTOLÓGICO DA FILOSOFIA DE FEUERBACH...}

\section{Fátima Maria Nobre Lopes}

estatuto ontológico materialista à sua filosofia que irá influenciar fortemente Marx, Engels, e depois Lukács na concepção e estruturação da ontologia do ser social. Portanto, o caráter ontológico da filosofia de Feuerbach consiste justamente em protagonizar uma virada ontológica ao sustentar a materialidade do ser, pois, para ele, a verdade é o homem e a vida, e não a razão abstrata ou o pensamento desligado do real. Em suma, trata-se da relação material entre o ser e o pensar, cuja primazia é do ser, quer dizer, o ser se sobrepõe ao pensar.

Sobre as contribuições de Feuerbach para o pensamento de Marx Bloch destaca "a importância de Feuerbach para a formação do marxismo", esse reconhecimento consiste no seguinte: "sem considerar o homem igualmente como um 'objeto sensorial' teria sido muito mais difícil elaborar no nível materialista o humano como raiz de todas as coisas sociais. O materialismo antropológico de Feuerbach designa assim a transição possível facilitada do materialismo meramente mecânico para o histórico.” (Bloch, 2005, vol. I, p. 250).

Portanto, não resta a dúvida de que o pensamento de Feuerbach exerceu uma influência inquestionável para a crítica de Marx ao hegelianismo e para a instauração de uma ontologia do novo tipo: a ontologia do ser social. Repetindo as palavras de Lukács: “a virada provocada por Feuerbach no processo de dissolução do hegelianismo teve caráter ontológico", por conseguinte, a nova orientação ontológica foi "iniciada com Feuerbach" (Lukács, 1979a, p. 12).

\section{Referências Bibliográficas}

BLOCH, Ernest. O Princípio Esperança. vol. 1. Trad. Nélio Schneider, Rio de Janeiro: EdUERJ, Contraponto, 2005.

FEUERBACH, Ludwig. Tesisprovisionales para la reforma de la filosofia.Lasedicionesliberales, Barcelona: Editorial Labor, 1976a.

Barcelona: Editorial Labor, 1976b. Principios de la filosofia del futuro.Lasedicionesliberales, A essência do cristianismo. Tradução e notas de José da Silva Brandão. Campinas, SP: Papirus, 1988.

\begin{tabular}{|l|l|l|l|l|}
\hline Gonista Dialeatus & Ano 2 & n. 6 & Janeiro - Agosto 2015 & p. 120-129 \\
\hline
\end{tabular}


Preleções sobre a essência da religião. Tradução de José da

Silva Brandão. Petropólis, RJ: Vozes, 2009.

HEGEL, Friedrich. Enciclopédia das Ciências Filosóficas - 3 vols. Tradução de Artur Mourão. $1^{a}$ ed., Lisboa: Edições 70, 1992.

LUKÁCS, György. Ontologia do Ser Social - Os princípios ontológicos fundamentais der Marx. Tradução de Carlos Nelson Coutinho. $1^{\text {a }}$ ed., São Paulo: Ciências Humanas, 1979a.

Ontologia do Ser Social - A falsa e a verdadeira ontologia de

Hegel.Tradução de Carlos Nelson Coutinho. $1^{a}$ ed., São Paulo: Ciências Humanas, 1979b.

.Ontologia dell'EssereSociale- 3 vols. A cura di Alberto Scarponi, $1^{\text {a }}$ edizioni, Roma: Riuniti, 1976 (vol. I); 1981 (vol. II* e vol. II**).

ProlegomeniAll'OntologiaDell'EssereSociale: questionidi principio de un'ontoliaoggidivenutapossibile. Tradução de Alberto Scarponi. Milano: Guerini e Associatti, 1990.

Para uma Ontologia do Ser Social.Tradução de Carlos Nelson Coutinho, Mario Duayer e Nélio Schneider. São Paulo: Boitempo, 2012, vol. I.

Para uma Ontologia do Ser Social. Tradução de Nélio Schneider.

São Paulo: Boitempo, 2013, vol. II.

MARX. Karl e ENGELS. F. A Ideologia Alemã. Tradução de José Carlos Bruni e Marco Aurélio Nogueira. $4^{\text {a }}$ ed., São Paulo: HUCITEC, 1984.

MARX, Karl. Manuscritos Econômico-Filosóficos. Tradução de Artur Morão. Lisboa: Edições 70, 1964.

A Sagrada Família. Tradução de FianoHasse e outros. 2 ed, Portugal, Martins Fontes, s/d, 323p.

TERTULIAN, Nicolas. Uma apresentação à Ontologia do Ser Social de Lukács, IN: Crítica Marxista, no. 03. $1^{\text {a }}$ ed., São Paulo, Brasiliense, 1996, p. 54 a 69. 